\title{
A DIVISÃO BINÁRIA DISCURSIVA E GEOGRÁFICA DA CIDADE DE LOUVEIRA/SP
}

Victor Carreão*

\section{Resumo}

A cidade de Louveira/SP é conhecida pela divisão binária de seu espaço: a região do Bairro Santo Antônio e a região do Centro, formadas por bairros (unidades administrativas), mas utilizadas por jornais e louveirenses para caracterizar a cidade. À luz da Análise do Discurso (ORLANDI, 1999 e 2004), designações (GUIMARÃES, 2017) registradas pelo discurso jurídico-administrativo de Louveira e por seus moradores (em um meme) são analisadas.

\section{Palavras-chave}

Discurso urbano. Louveira. Análise do discurso. Designação.

\section{1) Introdução}

A designação do espaço urbano é objeto de pesquisa de muitos trabalhos inseridos na temática da Análise do Discurso. O discurso urbano é, para Orlandi (1998, p. 8), formado inicialmente pela "sobreposição do conhecimento urbano sobre a própria materialidade urbana (da cidade). Nessa indistinção, o real urbano é substituído pelas categorias do saber urbano, seja em sua forma erudita (discurso do urbanista), seja no modo do senso comum".

O saber, entendido por Orlandi (1984, p. 12) como o conteúdo técnico acerca de determinado campo, é mobilizado no discurso dos moradores de uma cidade, mas pode ter sua origem no discurso da administração pública ou do planejamento urbano embora o oposto também possa acontecer (como veremos mais adiante, na nomeação de novos bairros em uma cidade). Essa perspectiva de trabalho com o urbano é interessante, uma vez que todo o território da cidade está sob uma jurisdição políticoadministrativa, o que pode levar as denominações urbanas a se cristalizarem (ORLANDI, 1999, p. 08).

\footnotetext{
* Mestre e doutorando em linguística pela Universidade Estadual de Campinas. Desenvolve pesquisas relacionadas à sociolinguística e tem interesse na relação entre a linguagem e o desenvolvimento urbano (e cidades no geral).
} 
Entender o processo de cristalização de determinadas denominações no espaço urbano é um convite a analisarmos a história de uma comunidade. As designações do discurso administrativo municipal que são incorporadas pelos cidadãos trazem em si uma memória de sequências discursivas históricas, ou seja, estão relacionadas à história - e é nessa relação entre enunciados que o analista do discurso deve trabalhar. Dessa maneira, o que podemos inferir de uma denominação que não é encontrada historicamente e tampouco nos documentos oficiais de um município? É possível considerar uma denominação no espaço um ato de resistência - uma palavra que faz frente à tradição e história de um lugar?

Neste trabalho, objetiva-se verificar a denominação binária observada no município de Louveira/SP: as regiões do Bairro Santo Antônio e do Centro - em que existem bairros (como unidades administrativas) cujas áreas são referidas, habitualmente, apenas por essas duas denominações. Para tanto, nosso recorte a ser analisado é um meme humorístico, retirado de uma página do Facebook, que traz nessa divisão uma denominação para o Bairro Santo Antônio que não é encontrada nos documentos oficiais louveirenses: Quebra. Os documentos jurídico-administrativos do município mostram como o território de Louveira cresceu e se desenvolveu desde sua emancipação. Através do trabalho com paráfrases (ver BARBOSA FILHO, 2012a), a análise aqui empregada busca verificar se a nova denominação para a região do Bairro Santo Antônio (também referido apenas como Bairro) pode ser entendida no sentido de resistência a políticas públicas de urbanização, que, como veremos mais adiante, nem sempre contemplaram ambas as partes de Louveira na mesma medida.

A cidade de Louveira encontra-se a 71 quilômetros de distância da cidade de São Paulo/SP e a 27 quilômetros da cidade de Campinas/SP. Emancipou-se, em 21 de março de 1963, da cidade de Rocinha. Louveira é uma das dez cidades que fazem parte do Circuito das Frutas, no interior do estado de São Paulo, que é conhecido por suas características agrícolas e por sua forte cultura italiana.

Louveira ganhou destaque na mídia nos últimos anos: em 2012, foi avaliada como a quarta melhor cidade para se morar no Brasil; em 2014, foi classificada como a cidade mais desenvolvida do país - em uma análise que empregou como critério o PIB per capita (AMARAL, 2014, p. 01); em 2015, foi considerada a terceira cidade mais desenvolvida do Brasil e a primeira do estado de São Paulo (INFORMATIVO PTB, 2016, p. 8). A cidade de características rurais passou a grande polo logístico, marcada 
pela vinda de grandes empresas a seu território, pela vinda de migrantes de outras regiões do país e pela rápida urbanização.

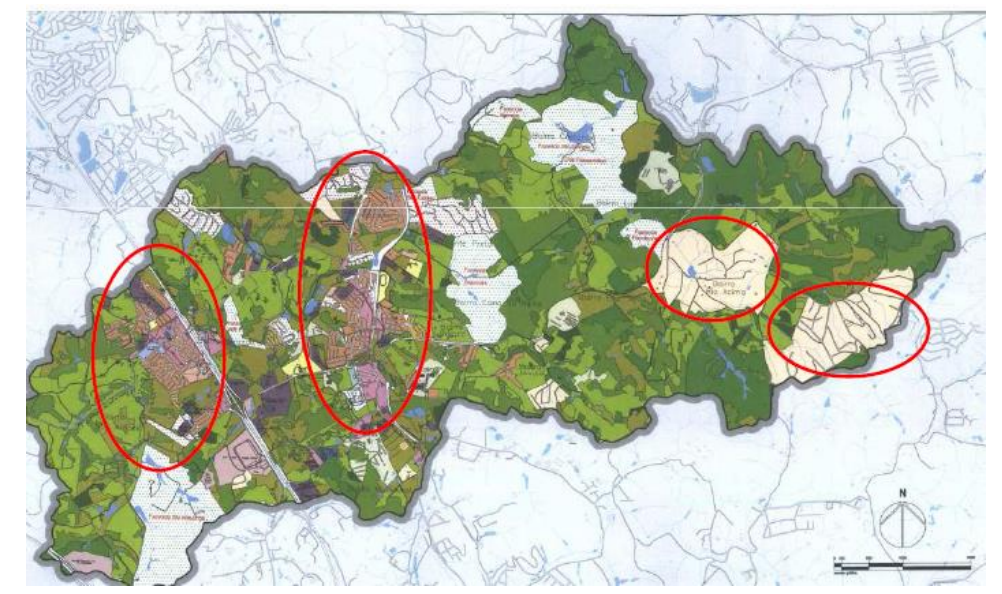

Figura 01: Núcleos urbanos de Louveira (PREFEITURA DE LOUVEIRA, 2016)

Na figura acima, a região destacada à esquerda é conhecida pelos louveirenses sob o nome de "Bairro Santo Antônio", "Bairro" ou "Quebra". A região demarcada ao centro da figura é conhecida pelos moradores da cidade como "Centro" ou "Louveira". Estas duas áreas são divididas geograficamente pela rodovia Anhanguera. As duas regiões menores à direita da imagem são os bairros do Monterrey e do Arataba, respectivamente, e estão na área de proteção ambiental de Louveira. Em nosso trabalho, exploraremos as designações feitas pelos louveirenses às duas primeiras regiões aqui mencionadas: o Bairro e o Centro ${ }^{1}$ (palavras adotadas, neste trabalho, para fazer menção às duas regiões, pois são comumente observadas nos jornais da cidade).

O Bairro conta com cerca de 25.000 habitantes, sendo, destes, cerca de 15.000 migrantes nordestinos que mudaram para a cidade em busca de melhores condições de trabalho e de vida (GUIN, 2014, p. 01). Seu território é constituído por Zonas de Uso Misto (como será detalhado mais adiante), em que residências e comércios podem dividir o mesmo espaço urbano. Já o Centro possui uma área menor de Zonas de Uso Misto e apresenta territórios classificados como Zona de Uso Residencial, cuja finalidade é a construção apenas de moradias. Há, assim, um contraste grande entre as duas regiões, uma vez que muitos condomínios de alto padrão são encontrados no Centro, enquanto a região do Bairro se vê passando pela regularização de "bairros irregulares", como, por exemplo, o caso do bairro da Vila da Conquista: lotes, de

\footnotetext{
${ }^{1}$ A menção feita a essas duas regiões será grafada com letra maiúscula: Bairro e Centro. Assim, visamos evitar confusão com termos como "bairro", no sentido de unidade jurídico-administrativo da cidade, ou "centro", quando nos referirmos à região central, geograficamente, de uma cidade.
} 
antigas fazendas, vendidos irregularmente que se transformaram em bairros, nomeados pelos próprios moradores (PREFEITURA DE LOUVEIRA, 2016). Há, assim, uma divisão de classe social entre as duas regiões: as ocupações de terrenos no Bairro são realizadas por famílias de classes sociais marginalizadas, enquanto, no Centro, os grandes condomínios servem de habitação para as classes sociais mais abastadas.

Comentários em entrevistas sociolinguísticas (CARREÃO, 2018, p.152, grifos nossos) auxiliam a ilustrar a percepção dos louveirenses sobre a ocupação do território. Destacamos um deles:

Louveira não se deixa crescer do lado de lá [Centro]. Você pode perceber que cresce desse lado [Bairro] e isso aí é uma conversa que a gente faz junto com o plano diretor do município e naquela área não é permitido muitas coisas. Entendeu? Porque eles querem segurar o crescimento. Eles acham que eles vão conseguir, mas o crescimento é natural.

Nas marcas dêiticas destacadas acima, é possível observar a divisão de Louveira em dois lados, aqui representando o Bairro e o Centro. Materializa-se, nessa textualidade, o planejamento da ocupação do espaço enquanto da ordem da gestão da cidade (a prefeitura) em conjunto com a população — o que, pelo comentário acima analisado, não parece ter ocorrido para a organização urbana do Bairro. A menção à administração municipal relaciona-se à tentativa de controlar o crescimento urbano, que para o louveirense é incontrolável. A tensão retratada nessa fala relaciona-se à questão do "consenso" nas decisões que concernem às políticas públicas e ao planejamento urbano gerido pela administração jurídica de um município - o "planejador" urbanístico.

Barbosa Filho (2012b, p. 14) destaca que a industrialização faz com que a intervenção do planejador seja necessária em um espaço, estando presente na ação do poder público - que é legitimada pela representatividade democrática advinda do consenso, estabelecido pela gestão pública em conjunto com os habitantes de determinada localidade. Orlandi e Rodríguez-Alcalá (2004, p. 13) mostram que a noção de "consenso" é fundamental para políticas urbanas democráticas: "o consenso pressupõe a inclusão de todas as partes e de seus problemas e proíbe a subjetivação política dos excluídos". O consenso é colocado em pauta, pois uma cidade é um aglomerado de diferenças, construída por diferentes comunidades e identidades - que podem ser bairros, ou até mesmo tribos (ORLANDI; RODRÍGUEZ-ALCALÁ, 2004, p. 16). Assim, o consenso auxilia na gestão das políticas públicas urbanas. 
A fala do urbanista, para Barbosa Filho (2012b, pp. 7-8), é tida como o "saber urbano ordinário". Quando é acrescentada à fala jurídico-administrativa, há a composição do "saber urbano especializado". É a circulação do "saber urbano especializado" que opera em um imaginário popular, como se refletisse a descrição absoluta do urbano: a fala das ruas sobrepondo-se à fala jurídico administrativa - ou, como posto por Barbosa Filho (2012b, p. 7), “a organização, o ordenamento, passa do plano urbanístico (plano do urbano) para o plano das relações no urbano". Os moradores de uma cidade passam a se referir ao espaço com designações sustentadas por esse discurso. Contudo, os sujeitos:

se movimentam não em um espaço vazio, mas em um espaço de interpretação afetado pelo simbólico e pelo político, dentro da história e da sociedade. Espaço que tem sua materialidade, sua não transparência. Espaço administrado, institucionalizado, organizado, calculado (ORLANDI, 2010, p. 5).

De maneira simples, Orlandi (2010, p. 6) traduz esse pensamento: “uma pessoa atravessando a rua experimenta sentidos do espaço urbano que difere de uma pessoa atravessando a cidade em um ônibus". É na cotidianidade que podemos observar, nesta sobreposição de sentidos, o "furo" materialmente linguístico que irrompe nas sucessivas camadas de memórias que compõem o discurso do aparelho jurídico administrativo. Por esse "furo", entendemos uma textualidade que irrompe nas camadas do discurso e da denominação já estabelecidos historicamente (seja no momento da elaboração das leis que nomeiam ruas e bairros ou na fala dos louveirenses que participaram da emancipação do município) e que, dessa maneira, reflete o deslizamento de sentidos. Um breve exemplo desse funcionamento, em Louveira, é o caso da formação do bairro da Vila da Conquista (mencionado anteriormente), rompendo a tradição da nomeação dos espaços pela gestão municipal. Esse bairro, assim nomeado por seus moradores, manteve o mesmo nome no momento de sua regularização, ato que só pode ser realizado pela gestão municipal e traz em si diferentes processos identitários:

As políticas públicas urbanas promovem, desse modo, mecanismos de identificação que constituem os sujeitos e, ao mesmo tempo, a materialidade do espaço que resulta de suas práticas, num processo que em seu funcionamento apaga o político. Pois o político não se confunde, em nossa perspectiva, com as políticas institucionais nem se situa apenas nos limites do que se convencionou chamar de "esfera política": o político diz respeito ao funcionamento das relações humanas, necessariamente marcadas por relações de poder, sendo ele 
estruturante de todas as instâncias da vida social (ORLANDI e RODRÍGUEZ-ALCALÁ, 2004, p. 19, grifos dos autores).

Processo similar o ocorre na divisão binária da cidade. Os bairros (enquanto unidades administrativas), desaparecem na fala dos louveirenses e nas chamadas de notícias de um dos principais jornais de Louveira, o Folha Notícias: o nome do bairro (enquanto unidade administrativa) só é mencionado nos casos de bairros recémaprovados pelo Plano Diretor do município; bairros mais tradicionais são englobados no Centro ou Bairro. Observamos, assim, que acontecimentos na cidade deságuam em diferentes possibilidades de textualidade: de um lado, "Bairro/Bairro Santo Antônio/Quebra", e, do outro, "Louveira/Centro". A possibilidade de substituir um nome por outro pode dizer muito sobre a designação:

No caso da relação entre designação e referência, o que se deve buscar é como um nome aparece referindo no texto em que ocorre. Assim é fundamental observar como o nome está relacionado pela textualidade com outros nomes ali funcionando sob a aparência da substituibilidade. Neste caso os conjuntos de modos de referir organizados em torno de um nome são um modo de determiná-lo, de predicá-lo (GUIMARÃES, 2017, p. 36, grifos nossos).

A divisão da cidade em duas regiões também é encontrada nas placas de sinalização rodoviária, quando se transita da rodovia Anhanguera, na altura do km 71, ao acesso da cidade: a sinalização aponta, para um lado, "B. Sto. Antônio" e, para o outro, "Louveira". Este é um exemplo de discurso administrativo que legitima a separação do território entre "Bairro Santo Antônio" e "Louveira" e nos leva a buscar nos documentos municipais indícios que reforcem essa divisão. Ao mesmo tempo, é necessário entender como a designação "Quebra" pode aparecer neste enunciado na posição de "Bairro/Bairro Santo Antônio". As possibilidades de denominação do espaço louveirense podem ser apresentadas no seguinte esquema: "A cidade de Louveira é formada pelo Bairro/Bairro Santo Antônio/Quebra mais Centro/Louveira”.

Observamos um enunciado dobrado — com a possibilidade da substituibilidade. Como realizado nos trabalhos de Barbosa Filho (2016; 2018), especialmente em Barbosa Filho (2016, p. 83), que exemplifica o enunciado "dobrado" no "processo empírico-artesanal da dobra, da plissagem, que deixa marcas visíveis: o papel quando dobrado ou plissado guarda visíveis as marcas da dobra, as marcas da fronteira mesmo quando desdobrado" - reflexão feita ao discorrer acerca do "enunciado dividido" citado por Courtine (2009). Assim, o enunciado dobrado trata de dois enunciados 
distintos, sem sentido único e linearidade, mostrando a fronteira entre uma materialidade da língua (o que permite deslizamentos de sentido). Apesar de serem aparentemente sinônimos, os signos Bairro Santo Antônio e Quebra, por exemplo, podem trazer com si diferentes cargas ideológicas. Os enunciados podem ser trabalhados a partir da paráfrase (como realizado nos trabalhos de Barbosa Filho (2012a e 2012b)). A paráfrase, conforme posta por Orlandi (1984, p. 11) é "o processo pelo qual procura-se manter o sentido igual sob diferentes formas". Buscar os sentidos por trás dessas denominações é o primeiro passo para entender a questão que colocamos neste artigo. Passemos ao recorte que nos auxiliará a entender o processo histórico dessas denominações.

\section{2) O recorte das designações louveirenses}

O recorte é, de acordo com Orlandi (1984, p. 14), "uma unidade discursiva. Por unidade discursiva entendemos fragmentos correlacionados de linguagem-e-situação. Assim, um recorte é um fragmento da situação discursiva" — isto é um exemplo de uma situação específica de interlocução. A imagem abaixo é de uma página do Facebook, "Louveira m1L Gr4u" (com postagens que humorizam o dia a dia dos louveirenses ${ }^{2}$ ), em 17/01/2017, e mostra a maneira pela qual os louveirenses percebem a cidade:

\section{ONDE VOGÊ MORA ?}

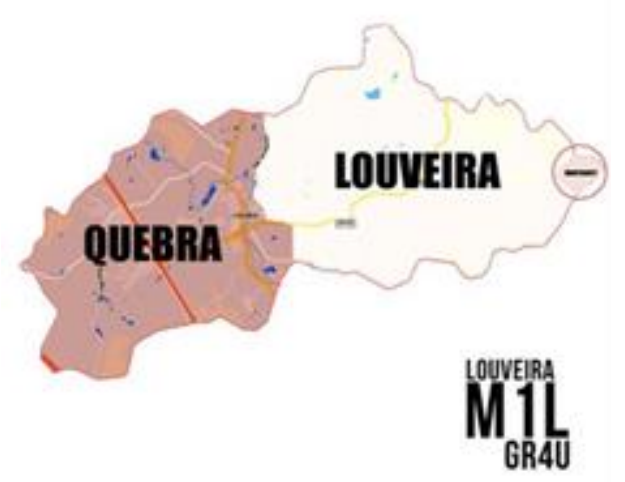

Figura 02: Postagem sobre o território louveirense (LOUVEIRA M1L GR4U, 2017)

\footnotetext{
2 A página tende a publicar conteúdo para os moradores da cidade, fazendo alusão a habitantes e estabelecimento populares entre os louveirenses. Chega, também, a enaltecer certas regiões ou a denegrir outras - como o caso de uma "rivalidade" com a cidade vizinha Vinhedo, ou até mesmo entre os próprios bairros louveirenses.
} 
Um efeito metonímico opera as designações do espaço na cidade de Louveira. Este será o recorte com que trabalharemos neste artigo: "Onde você mora: Quebra ou Louveira?". O nome Quebra é mencionado por alguns louveirenses mais antigos (CARREÃO, 2018, p. 29) como tendo origem na confusão entre moradores do Bairro e do Centro, no "quebra-quebra", que havia nos bailes e festas do Bairro Santo Antônio. Na legislação louveirense (Câmara de Louveira, 1977), há menção à "estrada do Quebra" como um dos pontos de demarcação do território louveirense. Outro comentário sobre a possível origem desse nome é o fato de a região do Bairro possuir o processo de "quebra do milho" em algumas plantações. É interessante verificar que a postagem do meme foi feita em 2017, mostrando que, mesmo muitos anos após a demarcação e denominação do território em Louveira, os moradores da cidade de Louveira utilizam uma nova textualidade para se referir à área do Bairro. Outro fato interessante são alguns comentários que aparecem nesta postagem: mais de um comentário aponta que a divisão apresentada na figura está errada, pois a região do Quebra se estende apenas até a rodovia Anhanguera (a linha vermelha do canto esquerdo da imagem); outro comentário aponta que o Quebra tem um McDonald's, enquanto a outra região do Centro não possui nenhum estabelecimento do tipo. Um comentário, com destaque em número de "curtidas", diz que a nomenclatura correta deveria ser "Nordeste vs. Louveira"3.

As designações do espaço louveirense operam com referências à historicidade, indicando a formação discursiva que atribui sentido às nomenclaturas do território. Barbosa Filho (2012a, p. 75), em sua dissertação de mestrado, faz um recorte de três modos da textualização da cidade: o discurso da ciência, sobre a fala dos especialistas do espaço; o discurso da administração pública, com estatutos, leis, planos e planejamentos; e o discurso cotidiano, a fala de rua. Neste trabalho, iremos nos ater ao discurso da administração pública.

\section{3) $O$ discurso jurídico-administrativo}

Como mencionado na introdução deste artigo, Louveira emancipou-se em 1963. Os primeiros documentos municipais que discorrem acerca da organização do espaço

\footnotetext{
${ }^{3}$ Há um grande número de migrantes nordestinos na população da cidade. É difícil verificar a intenção do autor desse comentário, no meme analisado, mas esta pode ser uma reivindicação da importância dos nordestinos no lugar ou uma crítica (preconceituosa) à migração.
} 
louveirense datam de 1965 e podem ser encontrados em um arquivo da Câmara Municipal (CÂMARA MUNICIPAL DE LOUVEIRA, 2019). Buscando por documentos que apresentem o zoneamento da cidade, constituímos nosso corpus de pesquisa. Os acontecimentos históricos em Louveira, de sua emancipação à sua urbanização, permeiam a designação de seus espaços, como veremos a seguir.

A Câmara Municipal de Louveira, em sua lei no 10/65, define a "zona central" da cidade como o que hoje é conhecido por Centro. Essa lei não dispõe nenhum comentário em relação à região do Bairro. Duas leis ordinárias, de 1968, detalham o zoneamento da cidade de Louveira da seguinte maneira: (i) a lei $\mathrm{n}^{\circ} 119 / 68$ delimita o "perimetro [sic] urbano do Município de Louveira" (CÂMARA MUNICIPAL DE LOUVEIRA, 1968a); e (ii) a lei no 120/68 delimita o "perimetro [sic] urbano do Bairro de Santo Antônio" (CÂMARA MUNICIPAL DE LOUVEIRA, 1968b).

Estes documentos trazem os termos "Louveira" e "Bairro de Santo Antônio", o que assinala o próprio discurso jurídico-administrativo da cidade traçando a divisão da cidade nessas duas denominações. Em 1969, a lei no 178/69 (CÂMARA MUNICIPAL DE LOUVEIRA, 1969a) dá denominação "às ruas do perímetro urbano de Louveira", com apenas as ruas da região do Centro sendo nomeadas - outro reforço da separação entre as duas regiões da cidade. A lei 226/69 (CÂMARA MUNICIPAL DE LOUVEIRA, 1969b) estabelece mudanças em dois perímetros urbanos: o "perímetro urbano Central" e o "perímetro urbano do Bairro de Santo Antônio". Nesse momento, é colocado como designação o termo "Centro" (uma ressignificação de "Louveira"), que também aparece nas mudanças do perímetro urbano, em processo de expansão, no texto da lei $n^{\circ}$ 557/77 (CÂMARA MUNICIPAL DE LOUVEIRA, 1977). O discurso do zoneamento aponta para dois campos importantes: o urbano vs. o rural (ou "nãourbano", como as áreas de mananciais e proteção ambiental).

O uso de "Central/Centro" é mantido, para a região de Louveira/Centro, nas mudanças do perímetro urbano (em processo de expansão) no texto da lei $\mathrm{n}^{\circ}$ 557/77 de 1977 (CÂMARA MUNICIPAL DE LOUVEIRA, 1977). Uma maneira de verificar esta divisão (entre urbano e rural) é averiguar, nas leis de 1968, 1969 e 1977, como a demarcação do espaço é feita conforme as referências espaciais usadas nestes documentos. Algumas referências espaciais aparecem sob o nome de "estaca X" ou "ponto X", em que a latitude e a longitude do município marcam o que aqui entendemos por "terra vazia". Essas marcações são observadas para a demarcação do território do Bairro, porém, na demarcação do território do Centro, predominam as propriedades 
privadas como as referências cartográficas. Dessa maneira, as marcações em um "espaço vazio" passaram a ser consideradas "rurais" e aquelas nas pautadas pelas propriedades constituíram o "urbano". O embate entre urbano e rural podem auxiliar no entendimento dos processos de ressignificação encontrados na cidade de Louveira.

\section{4) Paráfrases e ressignificação dos espaços louveirenses}

Retornando o nosso recorte, o meme "Onde você mora: Quebra ou Louveira?", é possível perceber que a designação "Louveira" retoma uma memória de um discurso jurídico-administrativo, enquanto "Quebra" não é retomado por um interdiscurso de mesma natureza. O que se observa é, então, duas discursividades dividindo espaços de memória diferentes na mesma sintaxe de uma frase.

O enunciado inicia com o pronome interrogativo "onde", que se relaciona às opções "Quebra" e "Louveira", implicando uma relação com locativos. A operação do sentido de "onde" permite outras possibilidades de paráfrase, por exemplo: "em que bairro você mora" ou "em que região você mora". Contudo, o uso de "onde" em nosso recorte também permite uma leitura cujo sentido pode remeter a duas cidades distintas. Caso a pergunta de nosso recorte, “Onde você mora?", fosse posta a um louveirense, a provável resposta seria uma das duas áreas da cidade de Louveira (Bairro ou Centro), ainda que não fossem dadas essas opções de resposta no momento da pergunta. Neste caso, o funcionamento de "onde" se assemelha a uma exófora pressuposicional, apontada por Cardoso (1995, p. 163) como o termo que "estará remetendo a uma exterioridade específica àquilo que constitui o universo de referência do discurso ${ }^{4}$ ”. Por essa razão, o uso de "onde" na pergunta que constitui nosso recorte parece-nos um indicativo de que as regiões do Bairro e do Centro têm significados próximos, por exemplo, a duas cidades que operam com total autonomia, ou seja, separadas uma da outra. Podemos, também, pensar em qual o peso ideológico de utilizar "Quebra" ao invés de "Bairro Santo Antônio", por exemplo: a possibilidade de substituibilidade leva a conotações negativas ou ao pertencimento e/ou afeto pelo espaço? Entrevistas com louveirenses, centradas na questão do bairrismo, poderiam esclarecer melhor esse questionamento. O que buscamos, a seguir, é demonstrar como a evolução histórica de

\footnotetext{
${ }^{4}$ Nesse caso, ressalta-se que "discurso" não está entendido da mesma maneira que posto por Orlandi (2010), como o efeito de sentido entre interlocutores.
} 
Louveira, seu crescimento (e o que pode ser classificado como tal) resulta em textualidades linguísticas que apontam para a direção de que territórios podem requerer sua autonomia quando ultrapassam as restrições/limites impostos pela administração pública. Vejamos, abaixo, paráfrases (p) que exemplificam a ressignificação do espaço na cidade de Louveira:

(p1) Onde você mora: Quebra ou Louveira?

Pode ser reescrita das seguintes maneiras:

(p2) Onde você mora: Bairro Santo Antônio ou Louveira?

(p3) Onde você mora: Bairro Santo Antônio ou Centro?

(p4) Onde você mora: Bairro ou Louveira?

(p5) Onde você mora: Bairro ou Centro?

(p6) Onde você mora: Quebra ou Centro?

As paráfrases acima são possíveis e remetem às duas regiões da cidade de Louveira. Contudo, outra possibilidade de reescrita que coloca as significações em jogo de maneira mais explícita é a seguinte:

(p7) Onde você mora: Louveira ou Louveira?

O nome "Louveira" pode remeter à cidade de Louveira, o município, ou à região do Centro. É nessa ambiguidade que também podemos dizer que morar em X implica em não morar em Y:

(p8) Você não mora no Bairro;

(p9) Você não mora no Quebra;

(p9) Você não mora no Centro;

(p10) Você não mora em Louveira.

As paráfrases (p8) e (p9) mostram o efeito do apagamento: "você não mora no Bairro, logo mora no Centro", ou vice e versa. A paráfrase em (p10) também pode 
sintetizar o não pertencimento do Quebra à cidade. Pensando nos nomes dos bairros, enquanto unidades administrativas, é possível obtermos:

(p11) Onde você mora: Quebra ou Vila Nova?

(p12) Onde você mora: Quebra ou Jardim Niero?

(p13) Onde você mora: Vila da Conquista ou Centro?

(p14) Onde você mora: Altos da Colina ou Centro?

Não há, todavia, o mesmo efeito de sentido quando segmentos menores da cidade de Louveira são colocados em foco nas paráfrases acima. Esse processo nos faz questionar se utilizar o nome de bairros recém-regularizados (como a Vila da Conquista, por exemplo) soaria como um território que é parte da cidade de Louveira ou como uma área "anexa" a ele - uma classificação que merece mais detalhamentos.

Além de estar registrada nos documentos do planejamento urbano da cidade (CÂMARA MUNICIPAL DE LOUVEIRA, 1969a, 1977), uma menção “oficial” ao nome Quebra é feita em uma prova de concurso público, em 2007, para o cargo de professor de inglês: um mapa da cidade é colocado com diferentes pontos marcados por números ou letras; questiona-se qual é a região do mapa assinalada com um $\mathrm{X}$ e a resposta é a alternativa "O bairro Santo Antônio, popularmente chamado 'Quebra"” (ROTA DOS CONCURSOS, 2018). 2007 também é o ano em que o Plano Diretor da cidade passa por mudanças e redefinições no desenho da cidade.

O percurso, até aqui, deste trabalho buscou trazer a designação binária do território da cidade de Louveira e sua relação com a história do município — narrada, de certa maneira, pelo discurso jurídico administrativo municipal que guiou o desenvolvimento do planejamento urbano da cidade. Nos documentos da época da emancipação de Louveira (cf. CÂMARA MUNICIPAL DE LOUVEIRA, 1968a, 1968b, 1969a, 1977), é possível verificar que a área do Bairro tinha o objetivo de ser a área rural do município (com suas glebas e lotes), enquanto o Centro era caracterizado por suas propriedades e fazendas. Textualidades como "Louveira" e "Centro" já eram intercambiadas nesta documentação, enquanto do outro lado da rodovia Anhanguera o Bairro ainda era registrado como "Bairro de Santo Antônio", passando à redução de seu nome, em 1977, sem a preposição “de”: Bairro Santo Antônio.

As designações do espaço louveirense mudam conforme a cidade se expande e urbaniza. Os deslizamentos das textualidades dessas designações surgem na medida em 
que o efeito de sentidos muda: o Bairro de Santo Antônio é rural, mas soa para nós, ao considerarmos a documentação e as paráfrases até aqui realizadas, mais rural que Bairro Santo Antônio (sem a preposição “de”, conforme observado nas leis de 1977). Quando a textualidade de Bairro irrompe na sintaxe da frase, já é um Bairro mais urbano e moderno que Bairro (de) Santo Antônio, só não sendo mais urbano/moderno do que Quebra: "Quebra" só irrompe na fala louveirense após as recentes mudanças no espaço da cidade — até então só era referido por Bairro ((de) Santo Antônio). A dinâmica dos enunciados dobrados (cf. Barbosa Filho, 2012a, p. 38) é mais cristalizada para Louveira/Centro, que não passou pelas mesmas mudanças espaciais e sociais - um conservadorismo atestado e permitido pelo plano diretor da cidade. Um retorno aos documentos municipais de Louveira nos permite essa análise.

Tabela 01: Descrição da ocupação do solo de Louveira nos anos 2006, 2008 e 2013

\begin{tabular}{|c|c|c|}
\hline $\begin{array}{c}\text { Região/ano } \\
\text { do Plano } \\
\text { Diretor }\end{array}$ & 2006 e 2008 & 2013 \\
\hline \multirow{5}{*}{ Bairro } & Macrozona de Ocupação Controlada & $\begin{array}{l}\text { Macrozona de Estruturação e } \\
\text { Qualificação Urbana }\end{array}$ \\
\hline & $\begin{array}{l}\text { Zona exclusivamente residencial de baixo } \\
\text { adensamento }\end{array}$ & Zona de Uso Industrial \\
\hline & Zona mista de ocupação controlada & $\begin{array}{l}\text { Zona de Conservação Ambiental } \\
\text { Urbana }\end{array}$ \\
\hline & Zona mista de ocupação dispersa & Zona de Uso Misto 1 (ZUM-1) \\
\hline & Zona especial de produção agrícola & Zona de Uso Misto 2 (ZUM-2) \\
\hline \multirow{9}{*}{ Centro } & $\begin{array}{c}\text { Macrozona de Estruturação e Qualificação } \\
\text { Urbana }\end{array}$ & $\begin{array}{c}\text { Macrozona de Estruturação e } \\
\text { Qualificação Urbana }\end{array}$ \\
\hline & Zona exclusivamente residencial & Zona de Uso Industrial \\
\hline & $\begin{array}{l}\text { Zona exclusivamente residencial de baixo } \\
\text { adensamento }\end{array}$ & Zona de Uso Misto 2 (ZUM-2) \\
\hline & Zona de uso industrial diversificado & Zona de Uso Residencial \\
\hline & $\begin{array}{l}\text { Zona estritamente de preservação do patrimônio } \\
\text { histórico }\end{array}$ & $\begin{array}{l}\text { Zona de Conservação Urbana } \\
2 \text { (ZCAU) }\end{array}$ \\
\hline & Zona mista de ocupação concentrada & - \\
\hline & Zona mista de ocupação dispersa & - \\
\hline & Zona mista de ocupação controlada & - \\
\hline & Área de intervenção urbana & - \\
\hline
\end{tabular}

Fonte: Adaptado de PREFEITURA DE LOUVEIRA (2016) e CÂMARA MUNICIPAL DE LOUVEIRA (2006 e 2008)

As zonas destacadas em negrito, acima, são aquelas que se mantiveram na mudança de um Plano Diretor ao outro. Zonas de Uso Misto (ZUM) admitem, em seus territórios, construções residenciais e comerciais. Na ZUM-1 (no Bairro), os lotes residenciais devem ter, no mínimo, $140 \mathrm{~m}^{2}$ e os comerciais, $250 \mathrm{~m}^{2}$. É interessante 
observar que as restrições para a ocupação do solo por comércios, para a ZUM-1, contemplam imóveis maiores que as moradias ali permitidas. Na ZUM-2 (no Centro), os lotes residenciais têm o mínimo de $250 \mathrm{~m}^{2}$ e não há restrição para os lotes comerciais, limitados a "espaços para manobras, cargas e descargas no interior do lote" (PREFEITURA DE LOUVEIRA, 2013, p. 6). Já a Zona de Conservação Ambiental Urbana 2 (ZCAU) admite, em seu território, construções residenciais com o mínimo de $1.000 \mathrm{~m}^{2}$ : uma zona exclusiva para moradias, inexistente no Bairro.

Sabe-se que uma das motivações para essa mudança foi determinada pelo Tribunal de Justiça de São Paulo (2009, pp. 7-8), que aponta "que a concisão do Plano Diretor e a delegação de suas partes a leis regulamentadoras, como previsto, configurava uma burla à gestão democrática da cidade e à participação popular na elaboração do Plano Diretor”. Sobre a participação pública na elaboração do plano diretor (e outros instrumentos jurídicos relacionados às políticas urbanas), Orlandi e Rodríguez-Alcalá (2004, p. 11) apontam que:

as políticas urbanas atuais consideradas democráticas estão fundamentadas nessa lógica consensual: elas visam à constituição de uma "maioria" através do maior índice possível de "participação" dos "excluídos" e das "minorias sociais" nas diferentes instâncias da vida urbana, como as instituições jurídicas, culturais, tecnológicas, educativas, de lazer etc.

Quando o Tribunal de Justiça de São Paulo (2009) aponta que houve falha na gestão democrática da cidade, podemos imaginar que houve a exclusão de determinados grupos do planejamento da cidade ${ }^{5}$. Considerando as diferenças em relação ao uso do solo em Louveira, é importante que grupos de diferentes áreas da cidade participem do planejamento urbano. As restrições territoriais são mais evidentes na região do Bairro: não há uma zona exclusiva de uso residencial e de produção agrícola, pois o solo deve ser ocupado e utilizado para finalidades mistas: comércio e residências juntos. Isso difere - como já apontado na introdução sobre Louveira - do Centro, que possui uma zona destinada apenas a residências. Os discursos do Plano Diretor — também associados ao saber urbano que dá forma ao discurso jurídico-administrativo da cidade

\footnotetext{
${ }^{5}$ Durante as audiências públicas sobre a revisão do Plano Diretor louveirense, em 27 de março de 2019, houve o questionamento de um morador sobre o fato de a Associação de Moradores do bairro Santo Antônio não ter participado da revisão do Plano Diretor atual (elaborado em 2012) (FOLHA NOTÍCIAS LOUVEIRA, 2019). Esse fato está relacionado à elaboração do consenso.
} 
- abordam os temas da residência vs. outros usos (ou da proibição de áreas residenciais). A maneira pela qual essas duas áreas são denominadas também nos chama a atenção: o Bairro era, até 2013, uma macrozona de "Ocupação Controlada" descrita, pela Câmara Municipal de Louveira (2008), como uma área em que se deve "assegurar que o lançamento na natureza de qualquer forma de matéria ou energia não produza riscos ao meio ambiente ou à saúde pública, e que as atividades potencialmente lesivas ao ambiente tenham sua implantação e operação controlada".

As Zonas Mistas são aquelas destinadas à boa parte da população, que fica restringida a um espaço menor e que divide o espaço com comércios e indústrias. Ainda assim, a maior parte das zonas de interesse social para a população de baixa renda está no Bairro, espalhadas em outras localidades. São esses deslizamentos de sentidos que são percebidos pelos moradores de Louveira e que ganham forma na materialidade da língua, sustentada pela história.

A lei $n^{\circ}$ 120/68 (CÂMARA MUNICIPAL DE LOUVEIRA, 1968b) aponta que toda área ao redor do Bairro, em 1968, seria considerada como zona rural. O último Plano Diretor (PREFEITURA DE LOUVEIRA, 2016) incluiu, em áreas ao redor do Bairro, duas Zonas Especiais de Interesse Social II, cuja finalidade é a promoção de políticas habitacionais. Além disso, outros bairros irregulares foram regularizados (como o caso da Vila da Conquista, mencionado anteriormente). Entende-se, assim, que novos loteamentos no Bairro podem ser vistos como anexos ao território do Bairro Santo Antônio - bairro de unidade administrativa -, e sua caracterização como Quebra ou Bairro (enquanto forma reduzida do sintagma "Bairro Santo Antônio") pode indicar, também, essa mudança. Ainda pensando no Plano Diretor, observa-se que aqueles que moram no Bairro não possuem acesso aos condomínios fechados e aqueles que moram no Centro não possuem acesso às moradias populares:

(p15) Os condomínios fechados ficam no Centro;

(p16) Os conjuntos habitacionais ficam no Bairro;

De volta às sequências discursivas (p8) e (p9), percebem-se efeitos de valorização social: "Você mora no Bairro, logo você não mora em condomínios fechados" ou "Você mora no Centro, logo não mora em conjuntos habitacionais". Isso também nos leva a pensar no nome "Louveira" como se referindo à cidade e ao Centro e até que ponto a designação de "Bairro" e "Quebra" poderia operar de forma a 
simbolizar outra cidade. Outras paráfrases referentes à localização dos bairros nas duas regiões da cidade ajudam a visualizar os deslocamentos de sentido entre "Bairro" e "Quebra": dizer que "Vila Nova fica no Centro" e "Vila da Conquista fica no Bairro" pode implicar em leituras que apontam, em um processo de paráfrase, para "a zona residencial fica no Centro" e "a zona residencial irregular fica no Bairro". O discurso jurídico-administrativo é a principal memória evocada na designação dos espaços na cidade de Louveira, porém é trespassado por outras memórias concomitantes à expansão do Bairro e a contenção do Centro.

Podemos nos perguntar: como que as novas designações surgiram na boca do povo louveirense? Ou, "mesmo sem saber, por que o sujeito imprime esta e não aquela direção à argumentação?” (ORLANDI, 2004, p. 51). O próprio discurso jurídicoadministrativo forneceu as condições para que essa mudança ocorresse, não sendo em qualquer região do território louveirense. As paráfrases nos mostram, como já apontou Orlandi (2004, p. 52), que "quando uma palavra significa é porque ela tem textualidade, ou seja, porque a sua interpretação deriva de um discurso que a sustenta, que a provê de realidade significativa”. O Bairro não é mais a área rural delimitada pela prefeitura louveirense em 1968: é uma região com mais comércios e moradores do que o Centro e tão autônoma quanto ele - e é nesse momento de crescimento que "Quebra” surge.

Para os moradores do Bairro, a dinâmica econômica e de vida se transforma, e os sujeitos passam a perceber o ambiente de maneira diferenciada. O Bairro Santo Antônio passa a Bairro e passa a Quebra; não é o Centro, tampouco Louveira, mas também é a cidade de Louveira. As designações se sustentam em uma disputa de memórias que é encarnada na língua. Os bairros parecem se fundir em duas regiões, tornando binário um município diversificado, e podemos observar a nomeação do espaço sobrepondo as diferentes camadas de memória que significam Louveira. Quando o urbano rompe as fronteiras espaciais estabelecidas pelo Plano Diretor, uma nova textualidade irrompe no discurso dos louveirenses. Concluímos que o ponto central dessa análise, antes de passarmos às considerações finais, está na quebra do saber do urbanista - do objeto construído pelo discurso jurídico-administrativo - e da erupção de novos sentidos na narrativa louveirense, em que o imaginário sobre a cidade se sobressai na fala dos moradores da cidade. É possível entender as novas textualidades como resistência frente à urbanização louveirense que, de certo modo, descaracterizou o Bairro. 
$\mathrm{O}$ ato de renomear é uma oposição sutil, direcionada a instâncias que nem sempre agem com a mesma sutileza. É uma maneira de dizer que o sentido de algo "não é bem aquilo que já estava estabelecido", pois existe, ali, determinado grau de inadequação à forma que antes delimitava e continha suas características. A lei diz que uma porção de terra é vazia; é rural e não pode ser ocupada, mas, ao se levantarem os olhos do papel que contém a legislação, qualquer um pode ver que ali existem casas, pessoas, comércios e diferentes realidades coexistindo. A lei percebe que algo não é bem aquilo que já estava estabelecido e, visando obedecer a sua norma, tenta apagar o real (do urbano) para que ele se encaixe em suas diretrizes novamente. Mas, quando esse real subjuga o aparelho jurídico-administrativo, não há maneira da terminologia legal se sustentar: a resistência (nesse caso, urbana) irrompe na fala e mostra que (retomando a fala destacada na introdução deste trabalho) nem tudo pré-estabelecido é natural.

\section{5) Considerações finais}

Antes de sumarizar o percurso aqui feito, trazemos outra possibilidade que poderia explicar a separação entre Bairro e Centro: a construção da rodovia Anhanguera. Vale destacar a breve entrevista dada por Rubens Chicaglione à Câmara de Louveira (2018) em que diz: "Eu lembro quando começou a fazer a Anhanguera. Eu morava numa casinha beirando a quadra de uva do meu avô e quando foi fazer a Anhanguera quebraram a uva do meu avô no meio. E ele chorou, porque o sítio era até no Frango Assado e então cortou o sítio dele no meio". O corte da rodovia no território louveirense acentuou a divisão entre os dois lados, mas é importante lembrar que o zoneamento da cidade (anterior à época da rodovia) já havia previsto isso.

Guimarães (2017, p. 113) aponta que "os sentidos dos espaços da cidade são sentidos de uma divisão e redivisão constante do social. Redivisão que se expande e se resignifica [sic]'”. O que ocorre quando há uma fuga do discurso do saber urbano? Qual tipo de redivisão operou nesta mudança? Em um breve resumo do percurso que aqui realizamos, há duas textualidades em “Onde você mora: Quebra ou Louveira?”: há o discurso jurídico-administrativo que remete ao planejamento da região central da cidade, desde a época da emancipação, e o discurso que remete à expansão da região de “ocupação controlada" (CÂMARA MUNICIPAL DE LOUVEIRA, 2006 e 2008) do Bairro Santo Antônio; sua ressignificação que aponta para um "novo Bairro". A 
discursividade que opera na textualização de "Quebra" é um acontecimento cuja memória não é escrita, mas que está inscrita no discurso sobre a cidade, materializada na fala de seus habitantes. Os louveirenses são colocados em lugares nos processos de identificação/subjetivação a partir de um discurso jurídico-administrativo sobre o zoneamento municipal e, desse discurso, ressignifica-se a denominação do espaço louveirense.

O consenso se baseia em um "nós coletivo", na opinião pública que poderia satisfazer qualquer tipo de conflito (uma vez que, como já destacado anteriormente, se pressupõe a existência de um conflito para que haja a necessidade de um consenso). Entretanto, inúmeros dizeres, processos de significação e modos de existência são ignorados e, por conseguinte, apagados no processo consensual (deliberadamente ou não). Nas políticas públicas urbanas, a ideia de sociabilidade (a interação entre indivíduos nos territórios da cidade, por exemplo) é pautada pela exclusão em um processo tido como "democrático" e sustentado na encenação do consenso, sem o espaço real para o embate de posições. Como já apontado por Orlandi e RodríguezAlcalá (2004, p. 13), a existência de um verdadeiro consenso é ilusória: a construção do consenso é uma tentativa de silenciar a contradição; é uma ilusão que parte do imaginário democrático (em que todos têm direitos iguais), mas que não pode ser atingida. É esse conflito, também, que sustenta as novas textualidades.

\section{Referências}

AMARAL, Rafael. Segundo estudo, Louveira é a cidade mais desenvolvida do país. Jornal de Jundiaí, Jundiaí, 03 de Junho de 2014. Região. Disponível em: < http://www.jj.com.br/noticias-1144-segundo-estudo-louveira-e-a-cidade-maisdesenvolvida-do-pais >. Acesso em 03 mai. de 2015.

BARBOSA FILHO, Fábio Ramos. A escrita urbana nos (des)limites do (im)possível. Dissertação de mestrado apresentada ao Instituto de Estudos da Linguagem da Universidade Estadual de Campinas. Campinas, 106 f. 2012a.

Ordem e organização: algumas questões sobre razão e silenciamento na cidade. Revista Rua, v. 1, n. 18, p. 05-18, 2012 b.

CÂMARA LOUVEIRA. Entrevista: Rubens Chicaglione. Disponível em: < https://www.youtube.com/watch?v=tSLjwLc8h2Y\&list=PLxQC6fUxS_pNin3WPTIVGd96zjGi-9uA\&index=26 >. Acesso em 22 jun. 2018.

CÂMARA MUNICIPAL DE LOUVEIRA. Lei no 119/68. 1968a. Disponível em: < http://consulta.siscam.com.br/camaralouveira/arquivo?Id=29097 >. Acesso em 10 jul. 2018 
Lei n⿳ 120/68. 1968b.

Disponível em: < http://consulta.siscam.com.br/camaralouveira/arquivo?Id=29081>. Acesso em 10 jul. 2018.

Lei no 178/69. 1969a.

Disponível em: < http://consulta.siscam.com.br/camaralouveira/arquivo?Id=29577 >. Acesso em 10 jul. 2018.

Lei no 226/69. 1969b.

Disponível em: < http://consulta.siscam.com.br/camaralouveira/arquivo?Id=29377 >. Acesso em 10 jul. 2018.

Lei no 557/77. 1977.

Disponível em: < http://consulta.siscam.com.br/camaralouveira/arquivo?Id=28659 >. Acesso em 10 jul. 2018.

LEI MUNICIPAL No 1.845, 6 DE NOVEMBRO DE 2006. Disponível em: < http://consulta.siscam.com.br/camaralouveira/documento?sigla=lo\&numero=1845 >. Acesso em 11 jul. 2018.

LEI MUNICIPAL No 2.009, DE 2 DE DEZEMBRO DE 2008. Disponível em: $<\mathrm{http}$ ://consulta.siscam.com.br/camaralouveira/documento?sigla=lo\&numero=2009 >. Acesso em 11 jul. 2018.

Legislação Digital. 2019.

Disponível em: < http://consulta.siscam.com.br/camaralouveira/index/75/8 >. Acesso em 18 ago. 2019.

CARDOSO, Silvia Helena Barbi. Demonstrativos e o fio do discurso. Rev. Est Ling., Belo Horizonte, ano 4, v. 2, p. 157-177, jul./dez. 1995.

CARREÃO, Victor. Transformações econômicas e mudança linguística: a língua em Louveira/SP. Dissertação de mestrado. Programa de Pós-graduação em Linguística, Universidade Estadual de Campinas, Campinas, 164 f. 2018.

COURTINE, Jean-Jacques. Análise do discurso político: o discurso comunista endereçado aos cristãos. São Carlos: EDUFSCAR, 2009.

FILIPPI, Matheus. Cidades do Circuito das Frutas têm opções de turismo com muito sabor. G1, Campinas e Região, 20 jan. 2016. Disponível em: < http://g1.globo.com/sp/campinas-regiao/circuito-verao-das-

frutas/noticia/2016/01/cidades-do-circuito-das-frutas-tem-opcoes-de-turismo-commuito-sabor.html >. Acesso em 09 mar. 2018.

FOLHA NOTÍCIAS LOUVEIRA. Câmara realiza $1^{a}$ audiência para debater revisão do Plano Diretor. Cidades, 06 mar. 2019. Disponível em: < http://www.fn10.com.br/louveira-camara-realiza-1a-audiencia-para-debater-revisao-doplano-diretor/ >. Acesso em 11 mar. 2019. 
GOOGLE MAPS. Louveira. Disponível em < https://www.google.com.br/maps/@ 23.083137,-46.9334091,13z >. Acesso em 09 mar. 2018.

GUIMARÃES, Eduardo. Semântica do acontecimento: um estudo enunciativo da designação. 4a ed. Campinas: Pontes Editora, 2017.

GUIN, Conrado. Nordestinos compõem grande parte do bairro Santo Antônio. Jornal de Jundiaí, JJ nos bairros, 19 out. 2014. Disponível em: < http://www.jj.com.br/noticias-7294-nordestinos-compoem-grande-parte-do-bairrosanto-antonio >. Acesso em 04 mar. 2017.

INFORMATIVO PTB. Nossa Cidade Louveira. Informativo - Jan 2013 a Jun 2016. Revista informativa do Diretório Municipal do Partido Trabalhista Brasileiro Louveira, 2016.

LOUVEIRA M1L GR4U. Onde você mora? Louveira, 17 de janeiro de 2017. Facebook: Louveira M1L GR4U. Disponível em: < https://www.facebook.com/LouveiraM1LGR4U/photos/a.851429764931872.10737418 28.851427461598769/1286412751433569/?type=3\&theater $>$. Acesso em: 20 de mar. 2018.

ORLANDI, Eni Puccinelli; RODRÍGUEZ-ALCALÁ, Carolina. A produção do consenso nas políticas públicas urbanas: entre o administrativo e o jurídico. Escritos: Cidade, Consenso e Políticas Públicas, $\mathrm{n}^{\circ}$ 8. Campinas: Laboratório de Estudos Urbanos, 2004. p. 11-23.

ORLANDI, Eni Puccinelli. Segmentar ou Recortar. Série Estudos. Lingüística: Questões e Controvérsias, n 10, p. 9-26, Uberaba: Fiube, 1984.

A desorganização cotidiana. Escritos, Campinas, n. 1, p. 3-11, 1998. N/O limiar da cidade. Revista Rua Especial, Labeurb/Campinas, p. 7-19, 1999. . Cidade dos sentidos. Campinas, SP: Pontes, 2004.

Apresentação. In: ORLANDI, E. P. (Org.). Discurso e políticas públicas urbanas: a fabricação do consenso. Campinas: Editora RG, 2010. p. 5-11.

PREFEITURA DE LOUVEIRA. Uso, ocupação e parcelamento do solo no município de Louveira. 13 dez. 2013. Disponível em: < http://www.louveira.sp.gov.br/transparencia/administracao/leis/Lei\%202332\%20$\% 20$ Uso\%20e\%20Ocupa\%E7\%E3o\%20de\%20Solo.pdf >. Acesso em 02 dez. 2018.

Plano de Mobilidade Urbana Sustentável. 20. abr. 2016. Disponível em: < http://louveira.sp.gov.br/site/painel/dbarquivos/dbanexos/AudienciaPublicaPlanoMobili dadeUrbanaSustentavelLouveira.pdf >. Acesso em 07 jun. 2017.

ROTA DOS CONCURSOS. Questão Prefeitura de Louveira 2007. Disponível em: < http://rotadosconcursos.com.br/questoes-de-concursos/atualidades-e-conhecimentosgerais-louveira-sp >. Acesso em 15 jul. 2018. 
TRIBUNAL DE JUSTIÇA DE SÃO PAULO. Suspensão da vigência do Plano Diretor de Louveira. 2009. Disponível em: < http://www.mpsp.mp.br/portal/page/portal/cao_urbanismo_e_meio_ambiente/Jurisprude ncia/juris_urbanismo/TJSP-Ap-0011509-76-2009-8-26-0659-(jun-12)_Louveira.pdf >. Acesso em 11 jul. 2018.

\title{
THE DISCURSIVE AND GEOGRAPHICAL BINARY DIVISION OF THE CITY OF LOUVEIRA/SP
}

\begin{abstract}
The city of Louveira/SP is known for the binary division of its space: the district of Santo Antônio and the region of Centro, formed by districts (administrative units), but used by newspapers and louveirenses to characterize the city. Guided by Discourse Analysis (ORLANDI, 1999 and 2004), designations (GUIMARÃES, 2017) displayed by the legal-administrative discourse in Louveira and by its inhabitants (regarding a meme) are analyzed in this paper.
\end{abstract}

Key words

Urban discourse. Louveira. Discourse analysis. Designation. 